\title{
Os Impactos da Pandemia de Covid-19 nas Organizações da Sociedade Civil: CONJUNTURA, DESAFIOS E PERSPECTIVAS $1,2,3$
}

Camila Escudero ${ }^{4}$

\section{INTRODUÇÃO}

Atualmente, existem 781.895 organizaçôes da sociedade civil (OSCs) formais e ativas espalhadas por todos os 5.570 municípios brasileiros, segundo o Mapa das Organizaçóes da Sociedade Civil. ${ }^{5}$ Juntas, elas compóem um setor complexo, desenvolvendo um amplo rol de atividades que compreendem desde o planejamento e execução de projetos e políticas públicas; o relacionamento e estabelecimento de parcerias com os demais atores das esferas civil e governamental; até o aprimoramento e fortalecimento de mecanismos próprios de atuação (advocacy).

Frente a todos os limites e avanços conquistados pelas OSCs nos últimos anos, a atual conjuntura traz ainda novos desafios sobre a atuação das organizaçóes frente à pandemia de Covid-19, que assola o Brasil e o mundo em 2020.

Ao discorrer sobre a atuação de OSCs na área da saúde no Brasil, Ramos (2004) diz que não há dúvidas de que a presença e atuação das organizaçôes não governamentais (ONGs) no contexto da epidemia de Aids no país, saúde da mulher e reforma psiquiátrica (nos anos 1990) contribuíram decisivamente para a construção de políticas públicas e práticas de prevenção e assistência. Para a autora, essa participação se deu, em grande medida, devido às características de especialização, competência técnica e profissionalização de seus membros e tendência à proliferação de iniciativas e articulaçóes nacionais e internacionais. Nesse sentido, há motivos para se esperar que o mesmo campo de influência possa ser observado no caso da pandemia de Covid-19.

Assim, este artigo tem como objetivo destacar os impactos imediatos que a crise causada pela Covid-19 tem imposto às OSCs brasileiras, apontar alternativas e refletir sobre perspectivas, em um esforço de contextualização a partir de mapeamentos e descriçóes de perfis das organizaçóes em atividades no país.

\section{DADOS CONTEXTUAIS: PERSPECTIVAS A PARTIR DO TERRITÓRIO E ÁREA DE ATUAÇÃO}

A recente - e ainda escassa - literatura sobre a difusão de experiências práticas envolvendo OSCs e medidas de enfrentamento à pandemia de Covid-19 no país tem mostrado uma catalisaçáo de novas formas de atuação e mobilização, especialmente de OSCs concentradas na área de desenvolvimento

1. DOl: http://dx.doi.org/10.38116/bapi25art7

2. Uma versão preliminar deste artigo foi publicada em Escudero (2020).

3. A autora agradece a leitura atenta e sugestões de Janine de Mello, Felix Garcia Lopez, Mário Aquino Alves e Flávia de Holanda Schmidt no aperfeiçoamento deste texto.

4. Pesquisadora do Programa de Pesquisa para o Desenvolvimento Nacional (PNPD) na Diretoria de Estudos e Políticas do Estado, das Instituições e da Democracia (Diest) do Ipea. E-mail: <camila.escudero@ipea.gov.br>.

5. Disponivel em: <https://mapaosc.ipea.gov.br/>. 
e defesa de direitos e interesses, saúde e assistência social. A primeira categoria, por sua vez, é a que mais reúne OSCs no Brasil: são 279.075 em atividade no país. ${ }^{6}$

O fato de muitas áreas de atuação das organizaçôes se enquadrarem na categoria dos serviços públicos essenciais coloca algumas dessas entidades no epicentro da crise, na linha de frente de iniciativas voltadas ao atendimento da população afetada pela pandemia. Só na área de saúde são 7.986 organizaçóes ativas, sendo que, dessas, 3.181 têm atuação associada a equipamentos e instituiçóes hospitalares. A área de assistência social, por sua vez, contempla 42.223 instituiçóes e atendem diretamente grupos populacionais mais expostos a situação de vulnerabilidade. ${ }^{7}$ Ambas, somadas aos campos de atendimento à população em estado de vulnerabilidade, segurança, entre outras, foram consideradas indispensáveis ao atendimento constante da população durante a crise. ${ }^{8}$

TABELA 1

OSCs e área de atuação, território e características

\begin{tabular}{|c|c|c|c|c|c|c|}
\hline \multirow{2}{*}{ Região/estados } & \multicolumn{4}{|r|}{ OSCs } & \multirow{2}{*}{ População } & \multirow{2}{*}{ IDH } \\
\hline & Total & Saúde & Assistência social & Desenvolvimento e defesa de direitos e interesses & & \\
\hline Norte & 55.871 & 346 & 1.708 & 22.459 & 18.430 .980 & - \\
\hline Acre & 3.196 & 22 & 105 & 1.351 & 881.935 & 0,663 \\
\hline Amapá & 2.949 & 11 & 34 & 1.001 & 845.731 & 0,708 \\
\hline Amazonas & 10.326 & 50 & 323 & 3.547 & 414.459 .7 & 0,674 \\
\hline Pará & 21.985 & 130 & 622 & 9.788 & 860.286 .5 & 0,646 \\
\hline Rondônia & 7.895 & 68 & 282 & 3.109 & 177.722 .5 & 0,69 \\
\hline Roraima & 1.908 & 11 & 34 & 754 & 605.761 & 0,707 \\
\hline Tocantins & 7.612 & 54 & 308 & 2.909 & 157.286 .6 & 0,699 \\
\hline Nordeste & 194.033 & 1.345 & 8.891 & 92.931 & 570.716 .54 & - \\
\hline Alagoas & 8.152 & 72 & 262 & 3.157 & 333.735 .7 & 0,631 \\
\hline Bahia & 55.195 & 442 & 2.426 & 24.770 & 148.730 .64 & 0,66 \\
\hline Ceará & 32.469 & 262 & 1.723 & 16.506 & 913.207 .8 & 0,682 \\
\hline Maranhão & 24.309 & 70 & 989 & 13.741 & 707.518 .1 & 0,639 \\
\hline Paraíba & 14.831 & 89 & 411 & 7.261 & 401.812 .7 & 0,658 \\
\hline Pernambuco & 26.844 & 245 & 1.634 & 10.886 & 955.707 .1 & 0,673 \\
\hline Piauí & 13.334 & 52 & 523 & 7.645 & 327.322 .7 & 0,646 \\
\hline Rio Grande do Norte & 11.033 & 74 & 642 & 5.175 & 350.685 .3 & 0,684 \\
\hline Sergipe & 7.866 & 39 & 281 & 3.790 & 229.869 .6 & 0,665 \\
\hline Centro-Oeste & 63.154 & 568 & 3.156 & 7.906 & 162.970 .74 & - \\
\hline Distrito Federal & 14.682 & 138 & 510 & 4.646 & 301.526 .8 & 0,824 \\
\hline Goiás & 23.784 & 188 & 1.461 & 6.308 & 701.835 .4 & 0,735 \\
\hline Mato Grosso & 13.305 & 106 & 568 & 4.970 & 348.446 .6 & 0,725 \\
\hline Mato Grosso do Sul & 11.383 & 136 & 617 & 3.260 & 277.898 .6 & 0,729 \\
\hline
\end{tabular}

6. Disponível em: <https://mapaosc.ipea.gov.br/>.

7. Disponível em: <https://mapaosc.ipea.gov.br/>.

8. Lei oㅜ 13.979/2020, Decreto ํo 10.282/2020 e Decreto ํㅜ 10.292/2020. 
(Continuação)

\begin{tabular}{|c|c|c|c|c|c|c|}
\hline \multirow{2}{*}{ Região/estados } & \multicolumn{4}{|r|}{ OSCs } & \multirow{2}{*}{ População } & \multirow{2}{*}{ IDH } \\
\hline & Total & Saúde & Assistência social & Desenvolvimento e defesa de direitos e interesses & & \\
\hline Sudeste & 323.522 & 4.170 & 20.985 & 101.254 & 883.714 .33 & - \\
\hline Espírito Santo & 17.274 & 158 & 801 & 17.274 & 401.865 .0 & 0,740 \\
\hline Minas Gerais & 85.802 & 929 & 7.784 & 29.765 & 211.687 .91 & 0,731 \\
\hline São Paulo & 156.001 & 2.344 & 10.017 & 39.857 & 459.190 .49 & 0,783 \\
\hline Rio de Janeiro & 64.445 & 739 & 2.383 & 14.358 & 172.649 .43 & 0,761 \\
\hline Sul & 145.315 & 1.557 & 7.483 & 54.525 & 299.759 .84 & - \\
\hline Paraná & 488.93 & 448 & 3.121 & 175.52 & 114.339 .57 & 0,749 \\
\hline Rio Grande do Sul & 550.42 & 713 & 2.671 & 200.43 & 113.772 .39 & 0,746 \\
\hline Santa Catarina & 413.80 & 396 & 1.691 & 169.30 & 716.478 .8 & 0,774 \\
\hline Total & 781.895 & 7.986 & 422.23 & 279.075 & 2.101.471.25 & - \\
\hline
\end{tabular}

Fonte: Ipea, 2020; IBGE, 2019; PNUD, 2010.

OBS.: IDH - Índice de Desenvolvimento Humano.

A localização das OSCs também pode ser um parâmetro para compreender cenários. Sabe-se que ela acompanha, em geral, a distribuição da populaçáo, sendo as regióes Sudeste e Nordeste, as mais populosas, ${ }^{9}$ as que concentram maior número de entidades - 323.522 e 194.033 , respectivamente, ${ }^{10}$ e as que mais registraram casos confirmados e óbitos decorrentes da Covid-19. ${ }^{11}$

Consideramos, também, necessário verificar o IDH das localidades, uma vez que as entidades promovem açóes multidimensionais conducentes aos fatores que integram a composição do índice. A região Sul apresenta alto nível de IDH e é a terceira em quantidade de OSCs (145.315). Já a região Nordeste é a segunda em número de OSCs, ao mesmo tempo em que é região na qual todos os estados apresentam IDH mais baixos. Apesar de ser razoável supor que tal relaçáo seja significativa, reforçamos a necessidade de outros fatores de interação sejam considerados para uma análise mais definitiva.

Além desses índices, ainda, a categorização das OSCs em áreas como desenvolvimento e defesa de direitos e interesses; saúde; e assistência social, estabelecida pela Classificação Nacional de Atividades Econômicas (CNAE), completa o panorama contextual. Conforme destacado na tabela 1, as organizaçôes se concentram de modo volumoso nessas três áreas de atividades, reconhecidamente essenciais nas políticas e açôes para enfrentar a Covid-19.

Ainda que seja razoável ponderar a capacidade de relacionamento e intersecção entre as atividades relacionadas às três áreas aqui destacadas, há de se considerar os diferentes perfis das OSCs dentro de uma mesma área. Machado (2010) destaca uma delas, a saúde, a título de exemplo. Dessa forma, ele subdivide as OSCs relacionadas a ela como: i) perfil centrado na situaçáo da saúde; ii) perfil centrado na dinâmica hospitalar; e iii) perfil centrado na prestação de serviços. Segundo o site do Conselho Nacional dos Secretários de Saúde (CONASS), "se você olhar a participação das organizações sociais

9. A proximidade social e o contato pessoal é a maior forma de propagação do novo coronavírus, mas outros elementos influenciam nos resultados, como o acesso das pessoas a saneamento básico, hospitais etc. Disponível em: <https://www.paho.org/pt/covid19>.

10. Disponível em: <https://mapaosc.ipea.gov.br>.

11. A doença já foi registrada em $100 \%$ das regiões mais populosas do país. Disponível em: <https://www.icict.fiocruz.br/content/monitoracovid19-ferramenta-online-permite-monitorar-avan\%C3\%A7o-da-epidemia-no-brasil-dia-dia>. 
no apoio ao SUS, no enfrentamento dessa pandemia, você tem situações completamente diferentes, pois os modelos são diferentes pelo Brasil”. ${ }^{12}$

\section{EFEITOS PRÁTICOS E PONTUAIS DA PANDEMIA NAS OSCS}

As ações envolvendo as OSCs relacionadas à pandemia variam amplamente seguindo as características dos contextos nos quais estão inseridas. No entanto, dimensóes comuns se destacam com o desafio geral de organizar a manutenção das atividades frente ao novo cenário. Segundo Brechenmacher, Carothers e Youngs (2020), essa postura é natural em tempos de crise humanitária e desastre, uma vez que as OSCs, em geral, têm amplo conhecimento da comunidade e de redes locais, logo, ocupam posiçóes estratégicas para alcançar populaçóes vulneráveis com mais agilidade e, consequentemente, podem ter boa eficácia. Além disso, como atores sociais comprometidos em apoiar a sociedade civil - independentemente da área de atuação -, bem como com experiência em lidar com cenários adversos em seu cotidiano, é imperativo que se adaptem ao novo contexto, priorizando formas de ação relacionadas ao combate da Covid-19.

\subsection{Formas de movimentações de recursos financeiros}

Como forma de combate à Covid-19, uma das primeiras transações financeiras após o início da pandemia foi a transferência de dinheiro do governo federal aos fundos municipais e estaduais de saúde. ${ }^{13}$ Como os fundos permitem, tradicionalmente, autonomia na aplicação dos recursos - uma vez que se trata de um instrumento técnico com fundamentos legais e garantias administrativas voltado para a efetivação das propostas do Sistema Único de Saúde (SUS) -, é comum o repasse de valores às OSCs mediante o estabelecimento de parcerias. A administração desses recursos requer capacidade e esforços de gerenciamento e articulação das OSCs, bem como capacidade de monitoramento do Estado. Logo, é razoável pensar que as parcerias entre as organizaçóes e as esferas municipais e estaduais podem ser fortalecidas, trazendo inovaçóes em políticas públicas.

Outra movimentação do setor no que diz respeito a recursos financeiros, dessa vez no formato de doações, corresponde às OSCs de grande porte - representadas, principalmente, na figura das fundaçóes e institutos. No entanto, não há como prever se a dinâmica de doaçôes registrada será mantida ou está contextualmente ligada ao "ápice" da Covid-19. Registra-se ainda outras ações nesse sentido, entretanto, conjunta, revelando a capacidade de articulação e estabelecimento de parcerias envolvendo as OSCs. No que diz respeito às OSCs de menor porte, a criação de fundos solidários - especialmente por organizaçóes da área de desenvolvimento e defesa de direitos e interesses - despontam significativamente.

Vale considerar, também, a questão da crise financeira, consequência da Covid-19 em vários setores da economia, que forçam as OSCs a repensarem e adaptarem seus recursos previstos para 2020, pelo menos, para manutenção de sua sustentabilidade financeira e sobrevivência. Para as organizaçôes, podemos prever impactos diretos ou indiretos em diferentes tipos de fontes de receita. ${ }^{14}$ Seria necessário produzir balanço posterior para entender o impacto financeiro da pandemia sobre as organizaçóes.

12. Disponível em: <http://www.conass.org.br/covid-19-expoe-competencias-e-fragilidades-das-parcerias-entre-setor-publico-e-sociedade-civil/> . 13. Disponível em: <http://www.portaltransparencia.gov.br/comunicados/603503-portal-da-transparencia-divulga-gastos-federais-especificospara-combate-ao-coronavirus $>$.

14. Disponível em: <https://phomenta.com.br/o-impacto-do-coronavirus>. 


\subsection{Doações e mobilizações para pessoas em situação de vulnerabilidade e hospitais}

Algumas das ações das OSCs nesse momento são campanhas de arrecadação para ajuda de emergência, com a coleta de suprimentos médicos e equipamentos de proteçáo para hospitais, e o fornecimento de apoio a quem não tem outras formas de proteção social. Em vários lugares, atores cívicos colaboraram estreitamente com OSCs na doação dos chamados equipamentos de proteção individual (EPIs) e alimentos, principalmente na fase inicial da pandemia, contribuindo para os esforços de assistência de outras maneiras. Para Yasbek (2001), esse tipo de ação está alicerçado em um discurso humanitário da solidariedade e da filantropia, alavancado por uma moralidade fundada na premissa de ajuda aos mais necessitados.

Além disso, há organizaçóes, especialmente as concentradas na área de desenvolvimento e defesa de direitos e interesses, que direcionam seus trabalhos e atividades de combate à pandemia a grupos vulneráveis, seja prestando auxílio emergencial, seja pressionando autoridades por políticas públicas direcionadas. Mulheres, população carcerária, povos indígenas, imigrantes e idosos (esses últimos, um dos principais grupos de risco da doença) são alguns grupos de destaque nesse cenário.

Pires (2020) afirma que os segmentos sociais vulnerabilizados tendem a possuir menores capacidades de absorção dos variados impactos que as medidas abrangentes de enfrentamento à crise podem provocar em suas vidas, daí a necessidade de atenção específica. Condiçóes históricas e efeitos adversos colocam grupos minoritários em situação de maiores riscos sanitários, econômicos e sociais. Assim, medidas complementares que levem em consideração as situaçóes vividas por essa população podem contribuir, a curto prazo, para a contenção do contágio, e, a médio e longo prazos, para a reinserção e estabilização socioeconômica (Pires, 2020, p. 10).

\section{MUDANÇA ESTRATÉGICA NAS ATIVIDADES}

Além de novas iniciativas de ajuda mútua, muitos grupos estabelecidos da sociedade civil reorientaram seu trabalho de projetos de longo prazo para ações emergenciais. Para a maioria das organizaçóes humanitárias e de desenvolvimento, essa é uma mudança natural, se resguardadas as proporçóes do mission drift (Jones, 2007). "Embora os projetos ocorram praticamente em todas as organizaçóes e em todas as suas áreas e níveis, gerando produtos ou serviços para determinado público-alvo, demandam esforços de planejamento e execução específicos, devido às características de unicidade e a incerteza quanto aos seus resultados" (Silva, 2019, p. 194).

\subsection{Impactos dos atos normativos e jurídicos-legais da pandemia}

Desde o início da pandemia, uma série de leis, decretos, portarias etc. que implantam e regulamentam a situação de calamidade pública no Brasil, decretada pela União e alguns estados e municípios, tem atingido as OSCs. Uma das principais alteraçóes é com relação à celebração de novas parcerias no âmbito federal, entre governo e OSCs. A Lei no 13.019/2014 já previa, nos termos do art. 30, inciso II, a dispensa de chamamento público para novas contrataçóes em caso de calamidade pública no país. Como o Decreto Legislativo no 6/2020 instituiu o estado de calamidade pública, o chamamento público não é exigido no âmbito federal para a realização de parcerias com as OSCs (Mattos Filho et al., 2020, p. 7). A mesma situação se aplica a alguns estados e municípios em que a mesma medida foi adotada. Tal cenário é propicio à agilização e ampliação da atuação das OSCs em parcerias governamentais no esforço de combate à pandemia. Outro efeito da legislação emergencial 
é com relação à vigência dos contratos assinados entre OSCs e empresas ou governos, alguns aspectos fiscais e tributários, e alteraçóes nas relaçôes trabalhistas (Szazi et al., 2020).

\subsection{Comunicação, visibilidade e advocacy}

As OSCs também estão desempenhando papéis de destaque na disseminação de informaçóes qualificadas sobre a Covid-19. Tais informaçôes são essenciais também por conta da rápida difusão das chamadas fake news. Segundo Brechenmacher, Carothers e Youngs (2020, p. 3, tradução nossa), "grupos da sociedade civil se uniram para combater essa tendência, aproveitando sua experiência com a educação comunitária em áreas remotas ou carentes”.

Algumas OSCs monitoram ainda ações governamentais, ao cobrar açóes rápidas e eficazes dos dirigentes políticos, e fiscalizam a execução dos recursos. Para isso, geralmente, desenvolvem aplicativos nos quais cidadãos podem fazer denúncias ou mesmo receber informações sobre as principais frentes de fiscalização.

Destaca-se ainda a tendência de novas formas de comunicação das OSCs com seus stakeholders, com a concentração de comunicações e transações em canais digitais. Reuniôes e eventos on-line por meio de plataformas virtuais, shows de artistas transmitidos ao vivo pelo YouTube para arrecadação de recursos financeiros para manutenção das atividades da organização, crowdfunding (financiamento coletivo) para subsidiar projetos e açóes pontuais, extraordinárias e de interesse coletivo são algumas das iniciativas mais usuais. Outra ação verificada é a criação de portais com material exclusivo sobre a pandemia, podcasts e trocas de informação em redes sociais como Facebook, Instagram, Twitter e grupos de WhatsApp.

\section{CONSIDERAÇÕES FINAIS}

Se, por um lado, a atual situação de pandemia causada pelo Covid-19 permite dar visibilidade ao papel desempenhado pela sociedade civil organizada na provisão de bens e serviços, ainda mais em um contexto de escassez de recursos financeiros públicos e privados, bem como no fortalecimento das instituiçốes democráticas e participativas, por outro, os desafios impostos pelos possíveis impactos sociais e econômicos sobre as OSCs náo são poucos. Nesse sentido, sumariamos alguns pontos sobre a agenda das OSC na crise da pandemia do Covid-19, especificamente as relacionadas a seguir.

- A necessidade de as OSCs pensarem em atuaçôes de maneira articulada com o Estado, complementando ou suprindo lacunas. $\mathrm{O}$ enfrentamento da pandemia não é de responsabilidade única do poder público, apesar de sua coordenação ser feita pelo aparato estatal. Novas formas de gestão podem ser legados pós-Covid 19.

- A mesma articulação deve ser pensada no nível das OSCs. Juntar esforços e atuar em conjunto com outras organizaçôes formando redes colaborativas tendem a garantir mais visibilidade e alcance, e facilitar o acesso a recursos financeiros públicos e privados, além de otimizar recursos humanos, físico-estruturais etc.

- Readequar o orçamento previsto, entender e internalizar novos atos normativos e inovar em medidas para preservação das atividades realizadas (ou seu redirecionamento) e empregos dos colaboradores condizentes com as especificidades do terceiro setor é fundamental para a sustentabilidade financeira das OSCs e sua sobrevivência no futuro. Mais do que nunca, diversificar as fontes de recursos financeiros se mostra essencial em momentos pré e pós-crise. E ainda: defender que a filantropia e o investimento social privado possam continuar ou reforçar recursos para as OSCs de áreas que 
não estão diretamente ligadas ao enfrentamento da pandemia, como as atividades culturais, por exemplo, uma vez que, por conta do realinhamento global de recursos, tais campos tendem a perder suas fontes de receita.

- Torna-se urgente ainda investir em estudos e pesquisas científicas sobre o impacto da pandemia nas OSCs, novas formas de atuação e análises de como as ações desenvolvidas nessa situação podem contribuir para fomentar políticas públicas - nos níveis municipal, estadual e federal.

- Capacitar-se para a utilização das tecnologias de informação e comunicação (TICs) e de disseminação de informaçóes, dado que as ferramentas e possibilidades têm reflexos não apenas no conhecimento da situação, na troca, velocidade e ampliação de informaçóes, no acesso a recursos públicos e privados, mas, sobretudo, no estabelecimento de vínculos entre OSCs e seus stakeholders.

- Aproveitar a expertise das OSCs em mediar e/ou mobilizar o trabalho voluntário, bem como a capacidade de inserção local e articulaçóes comunitárias, especialmente das micro e pequenas organizações, pode ser estratégico para outros setores da sociedade, no que diz respeito a inovação e adaptação frente as adversidades.

\section{REFERÊNCIAS}

BRECHENMACHER, S.; CAROTHERS, T.; YOUNGS, R. Civil society and the coronavirus: dynamism despite disruption. Carnegie Endownment for International Place, Apr. 2020. Disponível em: <https://carnegieendowment.org/files/Brechenmacher_Carothers_Youngs_Civil_Society.pdf>. Acesso em: 6 maio 2020.

ESCUDERO, C. Os impactos da pandemia de Covid-19 nas organizaçóes da sociedade civil: conjuntura, desafios e perspectivas. Brasília: Ipea, 2020. (Nota Técnica, n. 67).

JONES, M. B. The multiple sources of mission drift. Nonprofit and Voluntary Sector Quarterly, n. 36, v. 2, p. 299-307, 2007.

MACHADO, G. S. O Serviço Social nas ONGs no campo da saúde: projetos societários em disputa. Serviço Social e Sociedade, São Paulo, n. 102, p. 269-288, abr./jun. 2010.

MATTOS FILHO et al. Covid-19 no Brasil: impactos a organizaçôes da sociedade civil, proteção de dados e fomento à tecnologia em saúde e questôes de imigração e refúgio. São Paulo: Mattos Filho, 2020.

PIRES, R. R. C. Os efeitos sobre grupos sociais e territórios vulnerabilizados das medidas de enfrentamento à crise sanitária da Covid-19: propostas para o aperfeiçoamento da açáo pública. Brasília: Ipea, 2020. (Nota Técnica, n. 33) Disponível em: <https:/www.ipea.gov.br/portal/images/ stories/PDFs/nota_tecnica/200408_nota_tenica_diest.pdf>. Acesso em 20 maio 2020.

RAMOS, S. O papel das ONGs na construção de políticas de saúde: a Aids, a saúde da mulher e a saúde mental. Ciência e Saúde Coletiva, v. 9, n. 4, p. 1067-1078, 2004.

SILVA, E. C. da. Elaboração e implementação de projetos sociais: desafios e perspectivas. In: JUNQUEIRA, L. A. P.; PADULA, R. S. Gestáo de organizaçóes da sociedade civil. São Paulo: Tiki Books: PUC-SP/PIPEq, 2019. p. 193-202. 
SZAZI, E. et al. OSC e COVID-19: impactos das medidas legais no dia a dia das organizaçóes da sociedade civil. São Paulo: SBSA Advogados, 2020.

YAZBEK, M. C. Pobreza e exclusão social: expressóes da questão social no Brasil. Temporalis, Porto Alegre, ano II, n. 3, 2001. 